\title{
Chapter 3 \\ Towards Inclusive Water Governance: OECD \\ Evidence and Key Principles of Stakeholder Engagement in the Water Sector
}

\author{
Aziza Akhmouch and Delphine Clavreul
}

\begin{abstract}
Citizens increasingly demand to be more engaged in how public policy decisions are made. In this environment, stakeholder engagement has emerged as a principle of good water governance. However, despite extensive research and case studies on the topic in recent years, the lack of evidence-based assessment on how effective engagement processes have proven to be in reaching intended objectives of water governance is striking. Most participatory evaluation exercises fail to provide decision-makers with the evidence they need to inform future engagement processes.

This chapter presents the key findings of an OECD study, which relies mainly on empirical data from a survey carried out across 215 stakeholders, within and outside the water sector, and derived from 69 case studies collected worldwide. It suggests an analytical framework to assess the impact of stakeholder engagement in waterrelated decision-making and policy implementation, based on interdependent components, i.e. drivers, obstacles, mechanisms, impacts, costs and benefits.

Results highlight the need for better understanding of the pressing and emerging issues related to stakeholder engagement. These include the external and internal drivers that trigger the engagement processes, the arrival of new entrants that ought to be considered, innovative tools that have emerged to manage the interface between multiple players and types of costs and benefits incurred by engagement at policy and project levels. The chapter concludes with policy guidance to decisionmakers and practitioners in the form of necessary conditions on how to set up the enabling environment for inclusive water governance.
\end{abstract}

Keywords Governance $\bullet$ Stakeholder engagement $\bullet$ Water policy $\bullet$ Water management $\bullet$ Inclusive

\footnotetext{
A. Akhmouch $(\bowtie) \cdot D$. Clavreul

Water Governance Programme, Organisation for Economic Co-operation and Development (OECD), 2 rue André Pascal, 75775 Cedex 16 Paris, France

e-mail: Aziza.Akhmouch@oecd.org; Delphine.Clavreul@oecd.org
} 


\subsection{Introduction: A Call for More Inclusive Water Governance}

Growing attention to inclusive water governance is motivated to a large extent by increasing pressure on water resources in many parts of the world. Future projections related to water are sobering: by the middle of this century, the world population will reach nine billion, four billion of which will live in severely water-stressed basins, whilst demand for water is expected to increase by $55 \%$ globally (OECD 2012). The challenges are huge, but they can be turned into opportunities. A number of water crises around the globe are primarily governance crises. In many circumstances, the problem goes beyond hydrology, infrastructure and financing; it is about who does what, at which scale, how and why. In a word, with the right governance approach, water could be a harbinger of progress.

Water governance is the 'the range of political, institutional and administrative rules, practices and (formal and informal) processes through which and how decisions are taken and implemented; decision-makers are held accountable in the development and management of water resources and the delivery of water services; and, last but not least, stakeholders articulate their interests and have their concerns considered' (OECD 2011).

Over the coming decade, decision-makers throughout the world will be forced to make tough choices about how to manage water in ways that are efficient, equitable and environmentally sound. Whether their efforts succeed may depend, in large part, on providing the broad range of stakeholders with a voice in water-related decisions that affect them. Stakeholder engagement holds the promise of improving acceptance and trust in water governance and reducing the potential for conflict over water issues.

Despite extensive research and case studies in recent years on the topic of stakeholder engagement, there is a lack of evidence-based assessment on how effective engagement processes have proven to be in reaching intended objectives of water governance. Most evaluations carried out on stakeholder engagement fail to provide decision-makers with the evidence they need to inform future engagement processes, rather calling for caution against generalising beyond the context of specific case studies (Abelson and Gauvin 2006). In that context, better evidence needs to be produced and policy guidance is required to encourage decision-makers and practitioners to engage with all stakeholders in the early stages of decision-making in order to secure support for water reforms, to raise awareness about water risks and costs, to increase water users' willingness to pay and to deal with conflicts.

This chapter presents key OECD evidence and messages on the main trends, drivers, obstacles, mechanisms, effectiveness, costs and benefits of stakeholder engagement practices in the water sector. It concludes by providing a set of principles for creating the enabling environment for inclusive water governance ${ }^{1}$.

\footnotetext{
${ }^{1}$ This chapter draws heavily on the OECD (2015a) report: 'Stakeholder engagement for inclusive water governance', OECD Publishing, Paris (OECD 2015a).
} 
Public acceptance and trust in water governance rely on inclusiveness and the capacity to accommodate a broad range of (often conflicting) interests across the water chain and policy cycle. A critical test of trustworthy and legitimate water governance is not just whether stakeholders are engaged but also whether they are actively playing their part. To guide public action in that direction, the OECD adopted Principles on Water Governance that set standards for more effective, efficient and inclusive design and implementation of water policies and which include a building block of stakeholder engagement (OECD 2015b).

\subsection{An Overview of Key Terms and Trends in Inclusive Water Governance}

Governments and public governance are becoming increasingly open. As countries are still coping with the consequences of the financial crisis, the public sector is facing acute challenges in terms of fiscal pressure with increased demands from citizens to be more engaged in how public policy decisions are taken. The general move from a 'top-down, hierarchical model' exerting sovereign control over the people and groups making up civil society to gradual involvement of public, nonstate actors such as private and not-for-profit organisations and sectors at different levels has characterised public policy since the 1990s.

Developing a common language represents one of the primary challenges to analysing the contribution of stakeholder engagement in the water sector. According to Smith (1983), public participation is defined as a range of procedures and methods designed to consult, involve and inform local communities and citizens (i.e. the 'public'). It typically refers to the involvement of individuals and groups in the design, implementation and evaluation of a project or plan (Brown and WyckoffBaird 1992; Yee 2010). However, the process of involving stakeholders has changed and is progressively moving away from mere 'participation'. It is no longer restricted only to 'civil society' and project-based approaches but attempts to address a broader range of actors in a more systematic way. This evolvement should be taken into account in the existing variety of concepts and vocabulary associated with stakeholder engagement.

Herein, stakeholder engagement is defined as the process by which any person or group who has an interest or stake in a water-related topic is involved in the related activities and decision-making and implementation processes. The person or group may be directly or indirectly affected by water policy and/or have the ability to influence the outcome positively or negatively (OECD 2015a).

Various degrees of engagement and different typologies of engagement and participation have been discussed in the literature. A well-known categorisation is the 'ladder of citizen participation' developed by Arnstein (1969) which identifies eight levels or 'rungs', ranging from manipulation (the lowest in the group of nonparticipation steps) to citizen control (the highest step and highest degree of citizen power). 


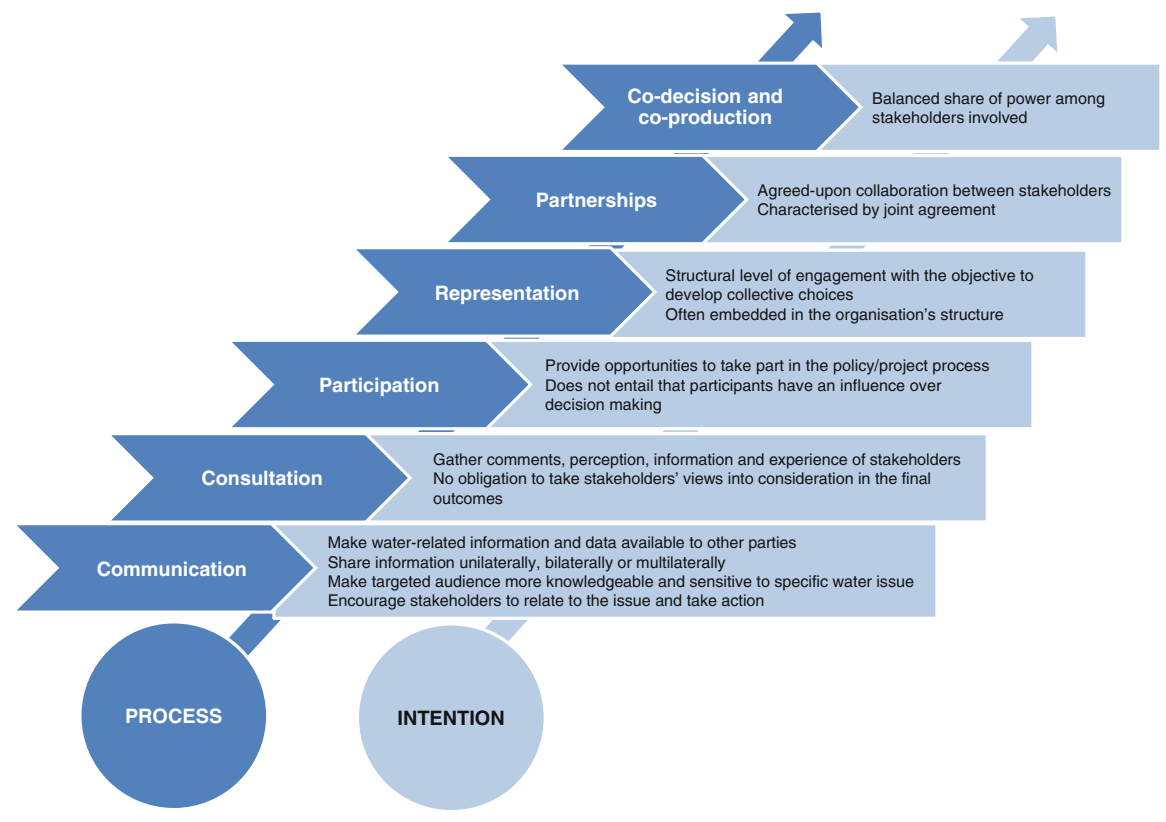

Fig. 3.1 OECD typology of levels of stakeholder engagement (Source: OECD (2015a))

This range shows that there is a significant gradation of citizens' participation. Arnstein's work has now been deemed obsolete and debatable because it considered participation as an end in itself rather than as a means (Wehn et al. 2014). Other typologies have emerged: Pretty (1995) 'typologies of participation'; Fung (2006) 'democracy cube'; and UNDP Water Governance Facility, Stockholm International Water Institute, Water Integrity Network (2013) 'levels of engagement'. This chapter distinguishes six levels of stakeholder engagement, depending on the process and the intentions being pursued (Fig. 3.1).

Overall, stakeholder engagement has been more institutionalised for water resources management than water service delivery. Legislation on surface water and groundwater quality and quantity and principles, such as integrated water resource management, has encouraged the creation of river basin organisations and their fora and the contribution of stakeholders to decisions related to planning. Engagement has been less systematic for water services and often consisting of handling customers' complaints despite the existence of consultation (rather ad hoc without consideration of the wider application) via shareholding, governing boards, regulatory policy and partnerships with citizens and users.

For a long period, stakeholder engagement in water governance remained mostly incidental, apart from some noticeable exceptions (e.g. the Polder approach in the Netherlands to build consensus (OECD 2014)). The flexibility associated with project- or issue-based stakeholder engagement has made it a preferred option for many decision-makers rather than engaging in more systematic inclusive approaches. It 


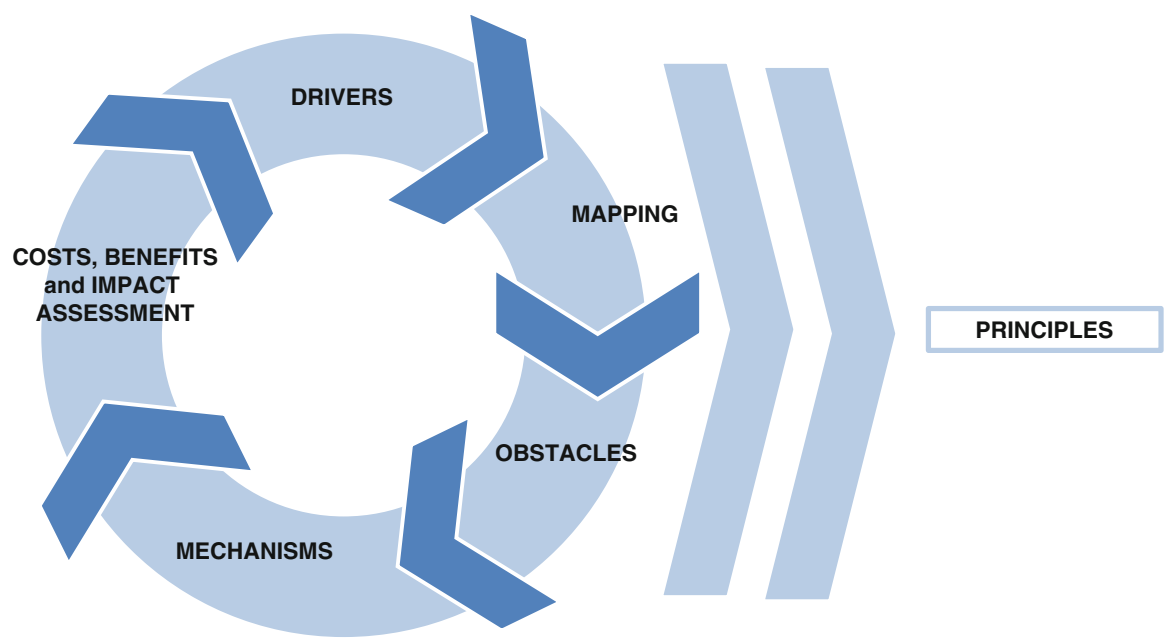

Fig. 3.2 OECD analytical framework of stakeholder engagement in water governance (Source: Based on OECD (2015a))

consists in setting up ad hoc mechanisms such as workshops, hearings, panels or campaigns to gather stakeholders around a specific issue. However, these engagement processes are often time bound, limited in scope and end conjunctly with the implementation or evaluation of the given project or policy. Stakeholder engagement processes have also been reactive rather than proactive. They tend to be a response to a need or an obligation, such as to comply with regulatory frameworks on the topic, or during crises and emergencies (droughts, floods, economic crisis, etc.) rather than being carried out on a voluntary basis.

Environmental, institutional and social trends within and outside the water sector have called for more inclusive governance and have spurred greater stakeholder engagement in water-related decision-making. On paper (de jure), regulations such as the Aarhus Convention, the EU Water Framework Directive and the EU Flood Directive mandate public engagement; however, in practice (de facto), the importance given to engagement and the extent of its implementation vary from one situation to another. This underscores the need to consider the effects of inclusive approaches on policy decisions.

The analytical framework suggested hereafter is organised around five mutually dependent components to look at stakeholder engagement holistically: (i) detecting drivers to understand the forces and levers for actions; (ii) mapping stakeholders in terms of their roles, responsibilities, influence, motivations, level of connectivity and scale; (iii) diagnosing obstacles and mitigating related risks to integrity, accountability and sustainability; (iv) identifying mechanisms that are fit-for-purpose; and (v) fostering evaluation to point out areas in need of improvements and trade-offs (Fig. 3.2). This framework can be used as a reading template to develop a comprehensive approach to engagement efforts and to decipher the actual contribution of stakeholder engagement to better water governance. 
To ground this analysis in sound evidence, a survey of stakeholder engagement in water governance was conducted in 2014 across 215 stakeholders with various levels of interest and experience in stakeholder engagement. Whilst the results of the survey provide valuable insights into and feedback on the reality of stakeholder engagement practices, they do not intend to be statistically comprehensive or reflect the multitude of views, arrangements and players in the field of water ${ }^{2}$. A compendium of 69 case studies was also collected worldwide to provide insight into practical experiences.

\subsection{Why Engage Stakeholders: The Driving Forces Behind Inclusive Water Governance}

The water outlook is not optimistic, and future economic, social, climate, urban and technological trends challenge water governance and the capacity of governments to address them, often calling for multi-stakeholder solutions. Pressure points over water allocation, infrastructure financing and disaster management require doing better with less money, less water and with more people willing to get on board. The daunting picture for the water sector in the future has prompted renewed emphasis on the role of stakeholder engagement across the public, private and non-profit sectors combined with structural and conjunctural drivers that have pushed stakeholder engagement to develop along different rationales.

A range of long-term structural drivers has resulted in a paradigm shift in water governance to better cope with future challenges. They can be clustered into four broad categories: climate change will affect water availability and resilience of water infrastructures, with different levels of impacts across the world; economic and demographic trends will drive water demand, in particular in cities, and affect the capacity of governments to respond (i.e. their ability to mobilise public funds); sociopolitical trends, such as the concept of IWRM, recent developments in European water-related policies, the United Nations Sustainable Development Goals will set new standards, regulations and aspirational goals paying greater attention to adaptive governance; and innovation and technologies will stimulate greater connectivity and new relationships, in particular related to web-based communication avenues.

Stakeholder engagement has also been triggered by conjunctural drivers and is greatly influenced by changing circumstances and situations (Fig. 3.3). Debates around water-related policy reforms and projects are primary drivers of stakeholder engagement. Stakeholders are more likely to take part in discussions when it concerns new policies they will have to uphold, whilst decision-makers look to consult and involve stakeholders likely to be impacted to ensure acceptability and sustainability of the policies to be implemented.

\footnotetext{
${ }^{2}$ Details of the survey's sample of respondents and methodology are provided in OECD (2015a).
} 


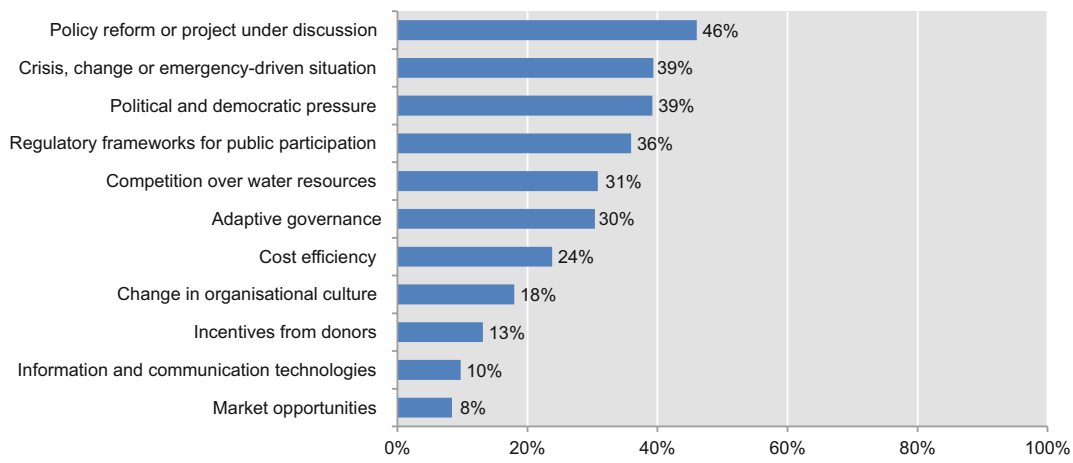

Note: The figure considers the drivers ranked from 1 to 3 on a scale from 1 to 11 .

Source: OECD Survey on Stakeholder Engagement for Effective Water Governance (2014).

Fig. 3.3 Recently identified drivers for stakeholder engagement in the water sector (215 respondents)

Survey results show that crises, change or emergency-driven situations, such as floods and droughts, are the second most important driver of stakeholder engagement. The community engagement initiative 'Rebuild by Design', for instance, was founded as a response to the devastation caused by Hurricane Sandy in the United States. Legal requirements on water-related stakeholder engagement have emerged in the past decade and boosted stakeholder engagement. In Japan, for example, the Japan Water Agency Law requires mandatory stakeholder mapping and engagement in all the activities of water agencies. Competition over water resources is considered the fourth driver. Engaging all actors impacted can support continuing dialogue on competing needs to be balanced and necessary trade-offs. In France, Électricité de France (EDF) signed a Water Saving Convention with major irrigators in the Durance Valley to improve water efficiency and allocation through improved local stakeholder engagement, which has led to a reduction in agricultural water consumption from 325 million to 235 million cubic metres.

Successful stakeholder engagement comes from a real understanding of the rationale that underlies it. It points to the reasons why engagement should or need to take place, for what outcomes and with which categories of stakeholders. In turn, decision-makers can define realistic and forward-looking policy objectives for stakeholder engagement and ensure that the processes are outcome-oriented.

\subsection{Who to Engage: Stakeholders, Their Motivations and Their Interactions at Different Scales}

A first step in the process of effective stakeholder engagement is to identify who they are and to determine what motivates them. Knowing who is responsible for what and at which level is an essential starting point and can help identify 
redundancies and gaps in the institutional framework that affect policy coherence and sector performance. Stakeholder mapping can be used to identify the core stakeholder functions in the sector and to assess how effectively they are carried out. Such mapping also highlights the interaction with, and the impact of stakeholders on, other areas that influence the water sector.

Beyond the 'traditional' actors, new players have gained interest and influence in water governance (Fig. 3.4). Whilst the role of the private sector has been inclined to focus on companies delivering water supply and sanitation, businesses have paid increasing attention to water governance in their strategies, especially to cope with regulatory risks and to secure water allocation. In parallel, citizens and water user associations have gained increasing influence over political decisions on water. As risks of floods intensify, property developers are also gaining influence, as spatial development generates long-term liabilities and financial implications in terms of water management, such as compensation for the loss of green areas and water amenities. They can play an important role in harnessing new sources of finance and contributing to the development of nontechnical solutions to manage floods. Institutional investors (e.g. pension funds, insurance companies, mutual funds) have also begun to factor environmental, social and governance issues into their decisionmaking process, and they are investing more and more in water infrastructure and utilities.

Some stakeholder categories are frequently excluded from the process. These include women (as the primary users of water in many parts of the world, for domestic consumption, subsistence agriculture and health), youth (as the future generation that will need to solve issues related to water), the rural and urban poor (as the main consumers in informal urban and rural settlements) and indigenous and aboriginal

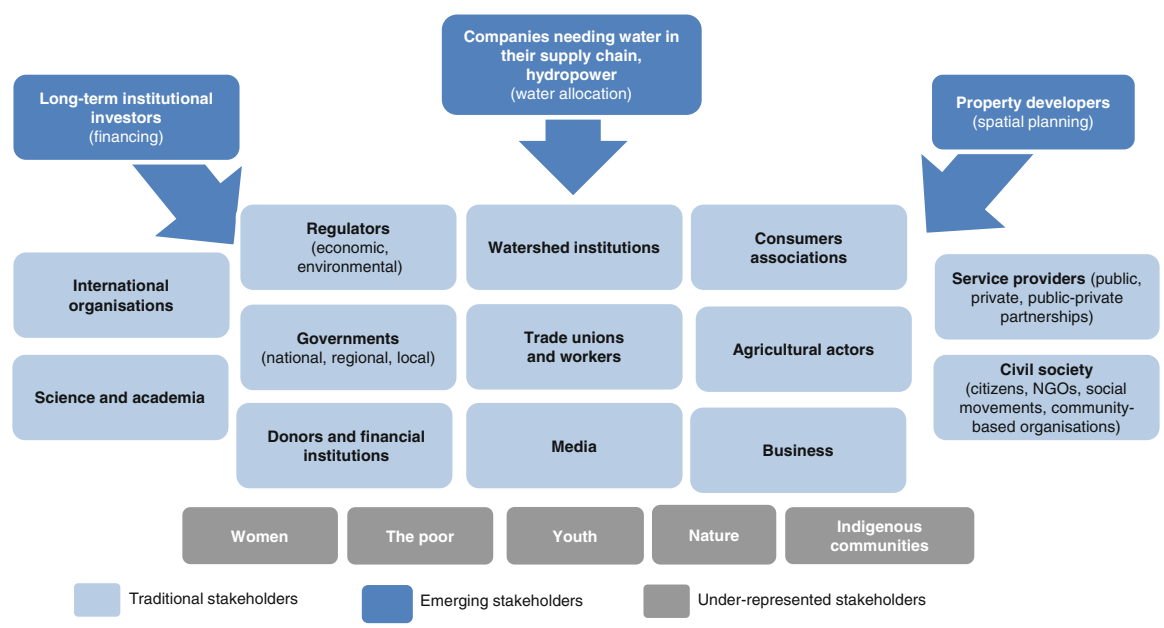

Fig. 3.4 Traditional, new and underrepresented stakeholders in the water sector (Source: OECD (2015a)) 
communities. Nature and other nonconsumptive users are also often absent from engagement processes. Greater efforts to encourage innovation are called for to connect and engage with these groups or individuals, who do not always come forward on their own. In order to gain a more balanced picture, it is very important to include these minority or 'less-vocal' stakeholders beyond formal engagement channels. In New Zealand, the Canterbury Regional Council launched an engagement process with district councils and the Māori tribal authority to develop and implement the new Canterbury Water Management Strategy based on a collaborative governance framework whereby 'local people plan locally'. It led to positive outcomes in terms of sustainability and resilience of water management in the region and to better community understanding of indigenous cultural values.

Stakeholders have different motivations, needs and interests. They aspire to different goals in water governance, whether these relate to water resource management - a primary concern mainly for national governments, businesses and international organisations; the supply of water and sanitation - mostly in the case of regulators and civil society; water disaster management; or environmental protection. Based on their core motivations, and often their mandate, stakeholders have different governance concerns that affect their willingness to contribute to waterrelated policies and projects as well as their degree of engagement.

The way they interact can also vary from place to place. Depending on their responsibilities and interest, stakeholders interact more or less with one another. Interactions amongst stakeholders tend to take place in silos, relying essentially on peer-to-peer exchanges, as is the case, for instance, for governments, river basin organisations, civil society, businesses and academics (Fig. 3.5). Understanding these dynamics is crucial to assessing the level of stakeholders' influence and engagement and to clarifying issues related to communication, trust, consensusbuilding and solidarity. For example, sociometric network analysis of American water utility professionals was carried out to shed light on the importance of exchange channels, amongst peers and opinion leaders, for innovation diffusion and knowledge-sharing in the municipal water industry.

Water is a field particularly sensitive to issues of scale. Water issues and hydrological boundaries cut across administrative frontiers. Water governance and water resource management take place at various spatial scales, both in their ecological and political dimensions. First, the hydrological system with its different levels from small catchments to large river basins plays a prominent role from the individual water body to the global climate. Second, competencies of political interventions have shifted both towards the national and supranational levels in the form of international agreements or the growing influence of the European Union; and towards the regional and local levels, in the form of decentralisation of water decision-making and implementation involving a diversity of local non-state actors.

Engagement processes range from local watershed groups negotiating over allocation practices to national committees debating priorities or international meetings seeking consensus about the management of transboundary basins between sovereign states. The issue of scale also relates to questions of democratic legitimacy. The higher the level of decision-making, the lower the possibilities for comprehen- 


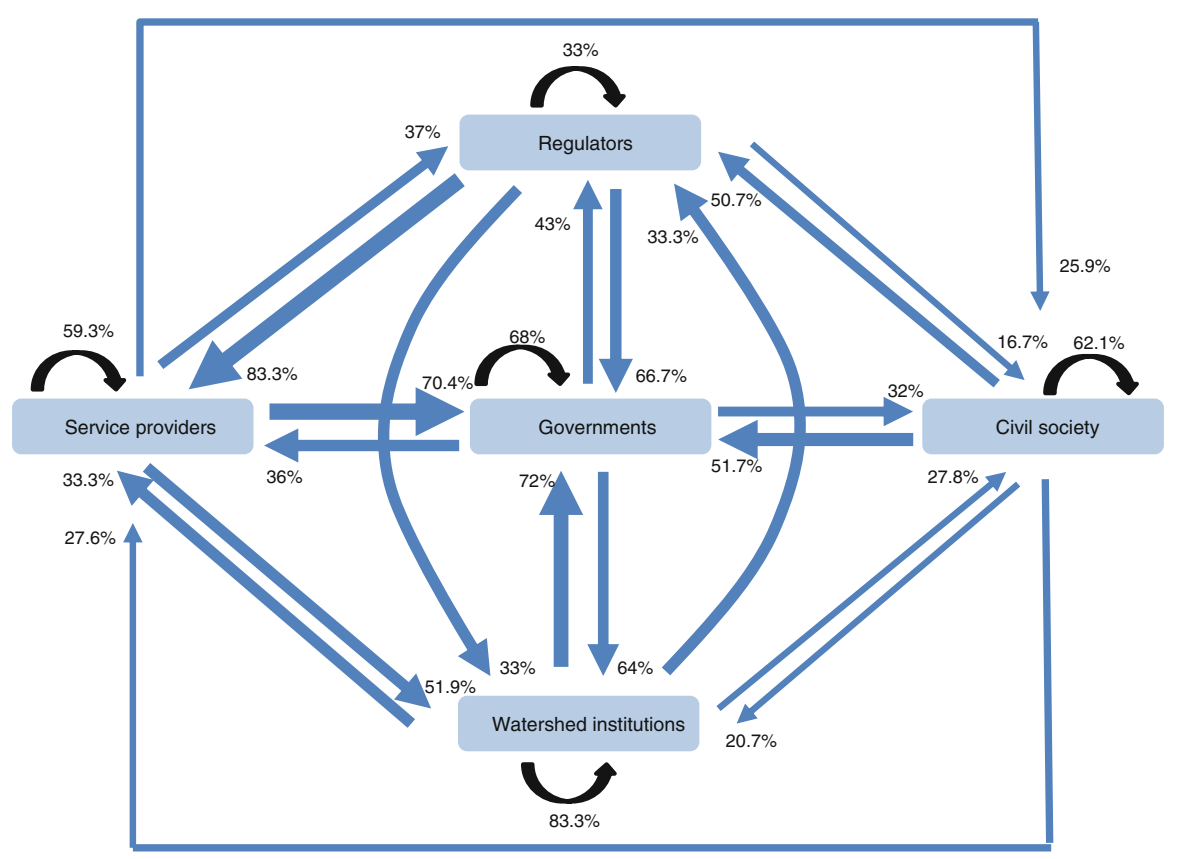

Fig. 3.5 Most frequent interactions across stakeholders in the water sector (Note: The figure shows the interactions across governments (national, regional, local), service providers, watershed institutions, regulators and civil society considered as 'very frequent'. The blue arrows represent interactions between the categories of stakeholders and the black arrows represent interactions within each category of stakeholders) (Source: OECD Survey on Stakeholder Engagement for Effective Water Governance (2014))

sive participation of all relevant constituencies and thus the higher the likelihood that conflicts may arise. Inversely, the lower the level of government, the more difficult it is to effectively address water governance problems, in particular those that are not strictly local, without having the big picture.

Stakeholder engagement can provide platforms to address the mismatch between administrative and hydrological scales. Water-related projects and policies can be driven by local livelihoods tied to local ecosystems or by energy producers making long-term production and investment choices at the national level. Thus, some stakeholders promote hydrological scales that correspond to manageable units in which they operate (e.g. river basin organisations). Others promote conventional administrative levels, arguing that this is where capacity, accountability and legitimacy already exist. In the Great Lakes region of North America, multilevel engagement processes on water resource management between the province of Ontario, municipalities, local NGOs and First Nation communities led to the formulation of common policy directions and long-term strategies for water protection. Fitting stakeholder engagement to place-based needs can help reconcile decisions within and across spatial scales. 


\subsection{Overcoming the Barriers to Inclusive Water Governance}

Engagement processes vary across places and stakeholders, but common barriers can be identified. Decision-makers need to carefully anticipate these bottlenecks and mitigate related risks (Fig. 3.6).

Respondents to the survey highlighted several major obstacles:

- First, the lack of political will and leadership: stakeholder engagement implies a shift in the balance of power including towards actors that may not share the same intentions, perspectives and interests.

- Second, the lack of clarity on the use of stakeholder inputs: if stakeholders with interest or influence do not understand how their input will contribute to decisionmaking, they may feel misled or manipulated by the process and will therefore lose interest. Satisfying all stakeholders' interests is a daunting task and implies the willingness to support the outcomes of the engagement process, even when they fail to coincide with one's vested and partisan interests. Clarifying the engagement process is one way to secure support and buy-in.

- Third, institutional fragmentation: responsibilities scattered across a multitude of actors create fissures in water governance with subareas administered independently and limited coordination incentives leading to poor consultation and weak accountability. The impact of institutional fragmentation is therefore often played out at the subnational level, with inadequate consultation on the needs of other related sectors, or subnational levels and overlapping responsibility. Fragmentation precludes the efficiencies and synergies that can be obtained through cooperation across authorities, water-related sectors and scales, and this can lead to policy outcomes focused on a specific issue or territorial area with little spill-over effect that can benefit the broader water sector.

- Fourth, the lack of funding: insufficient or unstable revenues to sustain the engagement process, logistical expenses related to meeting venues or support material and the lack of competent and dedicated staff are common bottlenecks, especially when government funding has been slashed in times of economic and financial crisis.

In addition, consultation 'fatigue' is a risk to avoid, and it helps to be clear and forthright about how people's input will actually be used. Engagement with broad groups helps to ignite the political will and the leadership required to deal with typical shortcomings, such as staff and funding, legal issues and inertia. Decisionmaking processes can also be hindered by conflicts of interest or consultation 'capture', especially when certain groups of actors and lobbies are better organised to voice their concerns. For instance, in some EU countries, farmers overrode engagement initiatives related to the implementation of the Water Framework Directive, leaving insufficient water for the environment (OECD 2014).

Decision-makers need to carefully anticipate bottlenecks to the integration of stakeholder engagement in water policy and projects and mitigate related risks. Different tools and procedures can help to achieve this. Translating existing stan- 


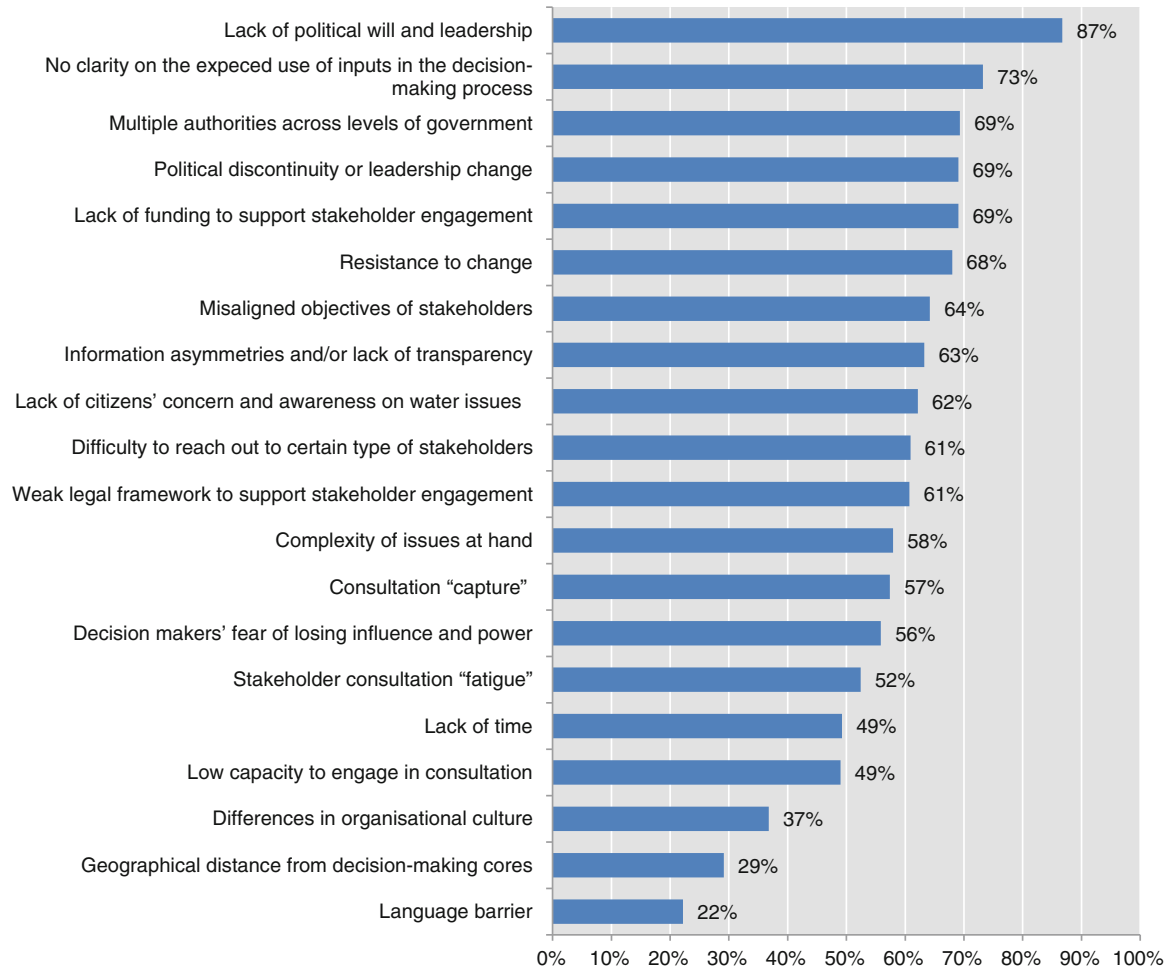

Fig. 3.6 Major obstacles to stakeholder engagement in the water sector ( 215 respondents) (Note: The graph considers the average response from the perspective of both targets and promoters for obstacles diagnosed as 'critical' and 'important' on a range from 'critical' to 'important', 'somewhat important' and 'not important', to the question 'which obstacles does your organisation face when taking part in or promoting stakeholder engagement?') (Source: OECD Survey on Stakeholder Engagement for Effective Water Governance (2014))

dards for inclusive decision-making into legislative frameworks can provide incentives to support the integration of stakeholder engagement. Defining strategies that make clear how stakeholder contributions will influence the final outcome can prevent frustration with regard to the influence stakeholders have over the process. Setting up information water systems and securing funds will also be critical to sustaining engagement processes in the long run. Engagement efforts should be allocated the same staffing and budget as other components of a water policy and project development process. Mechanisms designed to prevent the risk of undue access and influence by powerful, better organised influence groups are needed in tandem. Together with openness and engagement, solid integrity frameworks for policy-making can help ensure that final policy decisions reflect the views of the many and not just the few. Tools such as 'integrity pacts' and 'social witnesses' can also help to reduce the likelihood of conflict of interest and consultation capture, whilst ex post surveys on motivations can investigate levels of interest on specific water issues to set up the right incentives. 


\subsection{How to Engage Stakeholders: A Range of Formal and Informal Mechanisms}

There is a wide variety of mechanisms for engaging stakeholders, but they work differently according to place, time and objectives. Navigating this diversity and selecting the right mechanism(s) for engagement can be a daunting task for decision-makers. The survey helped identify 24 mechanisms that can be classified into 2 types: formal mechanisms (tools that have institutional or legal ground and often stem from an official agreement, a contract between parties or charters with clear operating rules and priorities) and informal mechanisms (not institutionalised but rather can be implemented at the discretion of the convener of the engagement process).

Stakeholders use some mechanisms more often than others. Meetings, workshops and expert panels were identified as the most often used mechanisms in the survey, followed by water associations and networks, stakeholder consultation as part of regulatory processes and river basin organisations (Fig. 3.7).

Innovative mechanisms and decision tools are gaining traction because of technological advances as well as greater skill and openness in applying the tools to discussion. The practical deployment of new information and communication technologies (ICT) has become a driving force of customised Internet platforms and

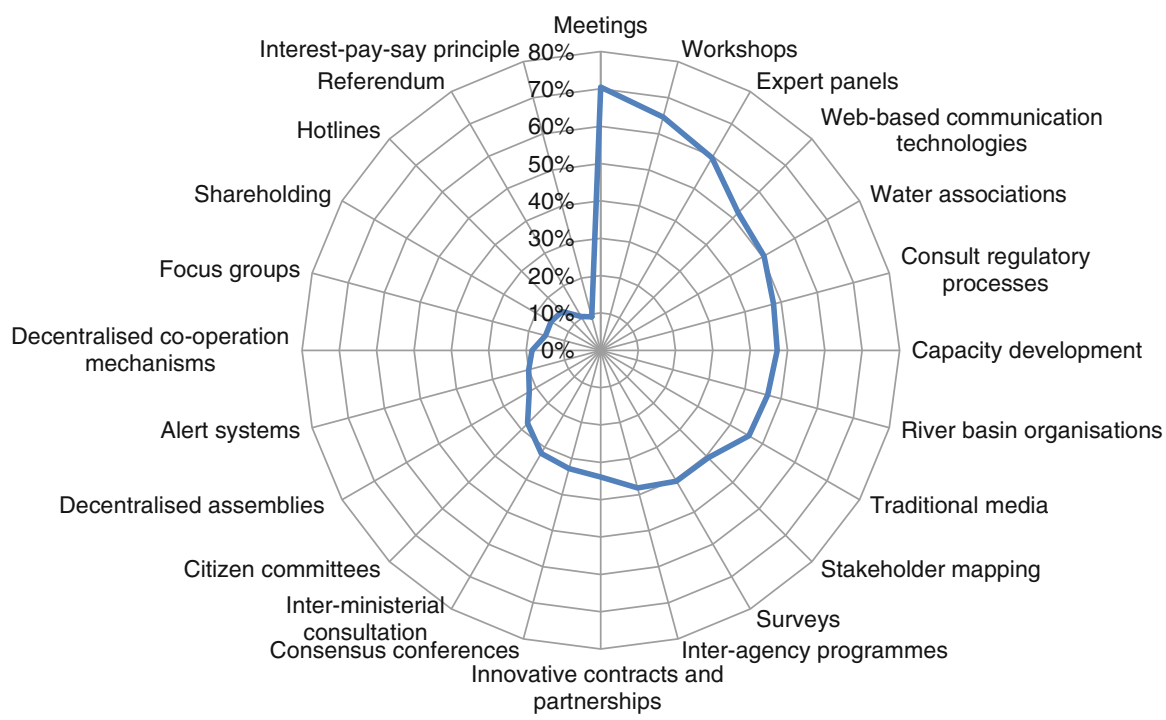

Fig. 3.7 Use of stakeholder engagement mechanisms in the water sector (215 respondents) (Note: The figure considers the average of 'yes' responses provided from the perspective of both targets and promoters to the question 'Which stakeholder engagement mechanisms does your organisation use or take part in?') (Source: OECD Survey on Stakeholder Engagement for Effective Water Governance (2014)) 
applications (Guimarães-Pereira et al. 2003), and the function of ICT platforms has taken new and varied dimensions as virtual meetings, and Internet-based platforms (social media, chat rooms, online fora) are used more frequently. E-participation has been used, for instance, to set up citizen observatories for flood risk management in the Netherlands and the United Kingdom where citizen participation was composed of a variety of citizen groups (volunteers, elected citizens, citizen scientists and communities) and rested on a range of communication modes from listening as a spectator to expressing and developing preferences on specific issues (Wehn and Evers 2014).

Efforts are still required to generalise digital tools in water decision-making and policy/project implementation, but in their various multilateral forms, ICTs are increasingly being used by decision-makers to help stakeholders better understand what they do. For instance, in Portugal the Water and Waste Services Regulation Authority (ERSAR) has developed a mobile app that provides relevant information to users on the quality of service provision across 278 municipalities.

These different mechanisms have their strengths and weaknesses (Fig. 3.8). Moreover, engagement modalities vary in terms of the amount of time they take, the number of stakeholders they involve and the amount of resources they require. Similarly, different policy tools may be applied to the different steps of the policy cycle (i.e. design, implementation or evaluation) or to different categories of actors.

It is crucial for decision-makers to carefully align tools with the level of engagement targeted and the context in which the engagement takes place. The effectiveness of mechanisms also relies on the capacities and resources needed for stakeholders to use them effectively, including knowledge, know-how and funding (travel expenses to attend a meeting, necessary technological settings). Also, new methods are being continually developed and require new skills and capacities. Thus, there is no one single optimal mechanism for stakeholder engagement but a menu of options for which the pros and cons need to be weighed up very carefully.

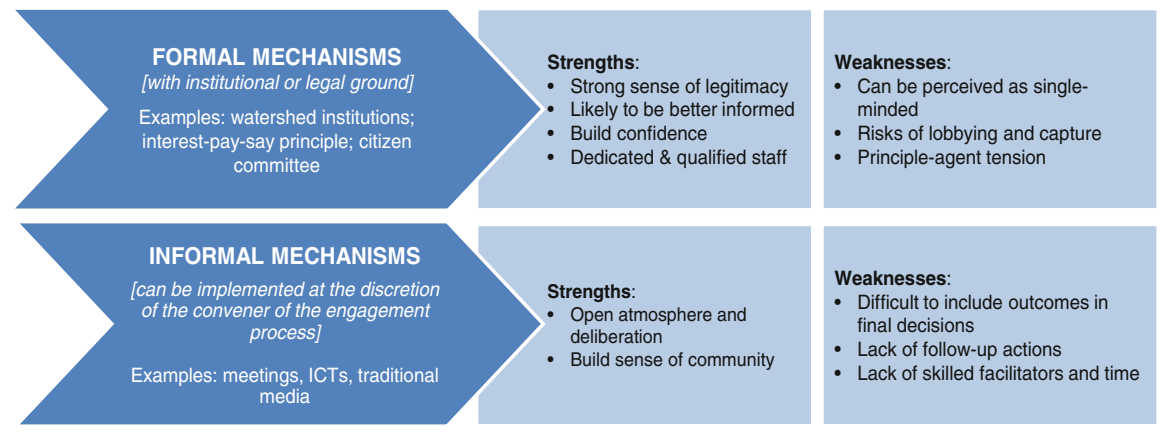

Fig. 3.8 Strengths and weaknesses of engagement mechanisms (Source: Based on OECD (2015a)) 


\subsection{Assessing Stakeholder Engagement: Effectiveness, Costs and Benefits}

There has been little evaluation of the effectiveness, costs and benefits of stakeholder engagement in the water sector, because this type of analyses is relatively new to the public sector. Evaluation has generally remained on an ad hoc basis, potentially because stakeholder engagement has often been carried out as an 'addon' to conventional processes, or a tick-the-box approach is frequently being used to comply with existing legislation and rules.

Assessing stakeholder engagement should not be considered as an end in itself but should serve a broader purpose of improving the process and its outcomes. It can:

- Strengthen the accountability of decision-makers, by measuring whether public and institutional resources, including stakeholders' time and effort, are effectively utilised

- Assist in determining whether the engagement process was successful and in drawing up an inventory of the lessons learnt towards future improvement

- Map out the potential challenges that may be encountered (e.g. divergent perspectives regarding flood defence measures between land planners, property owners and government authorities or regarding water resource allocation between farmers, industries and environmentalists)

Some difficulties may be experienced when evaluating stakeholder engagement. First, there is a lack of comprehensive frameworks of agreed-upon evaluation methods and reliable measurement tools. Second, there is a wide variety in the design and goals of engagement processes; therefore, evaluation frameworks should be general enough to apply across different types of processes, yet specific enough to have value for learning and practice. Third, stakeholder engagement is an inherently complex and value-laden concept; hence there are no widely held criteria for judging the success and failure of engagement efforts both in terms of process and outcomes.

Evaluation tools are increasingly being used to measure the success of engagement efforts. Multi-stakeholder meetings help to collect feedback on the level of performance of engagement processes; evaluation reports record the process (successes, failures, lessons learnt) and allow for analysis to improve future engagement processes. When publicly disclosed, these reports can shed light on how stakeholders' inputs were used and whether engagement was worthwhile. Other tools such as polls and surveys can provide information for assessing the engagement process, such as levels of satisfaction. Some stakeholder categories (e.g. civil society) use evaluation mechanisms more often than others. There may be a perception that customer feedback on a given stakeholder engagement process, particularly in terms of complaints, should be avoided. However, complaints can be useful warning signs that the process can be improved. 


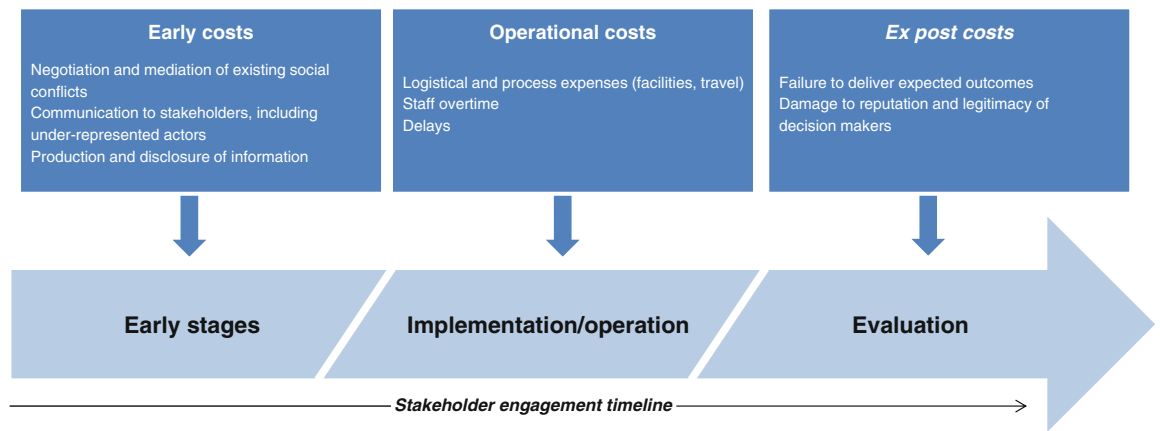

Fig. 3.9 Categories of costs in stakeholder engagement (Source: OECD (2015a))

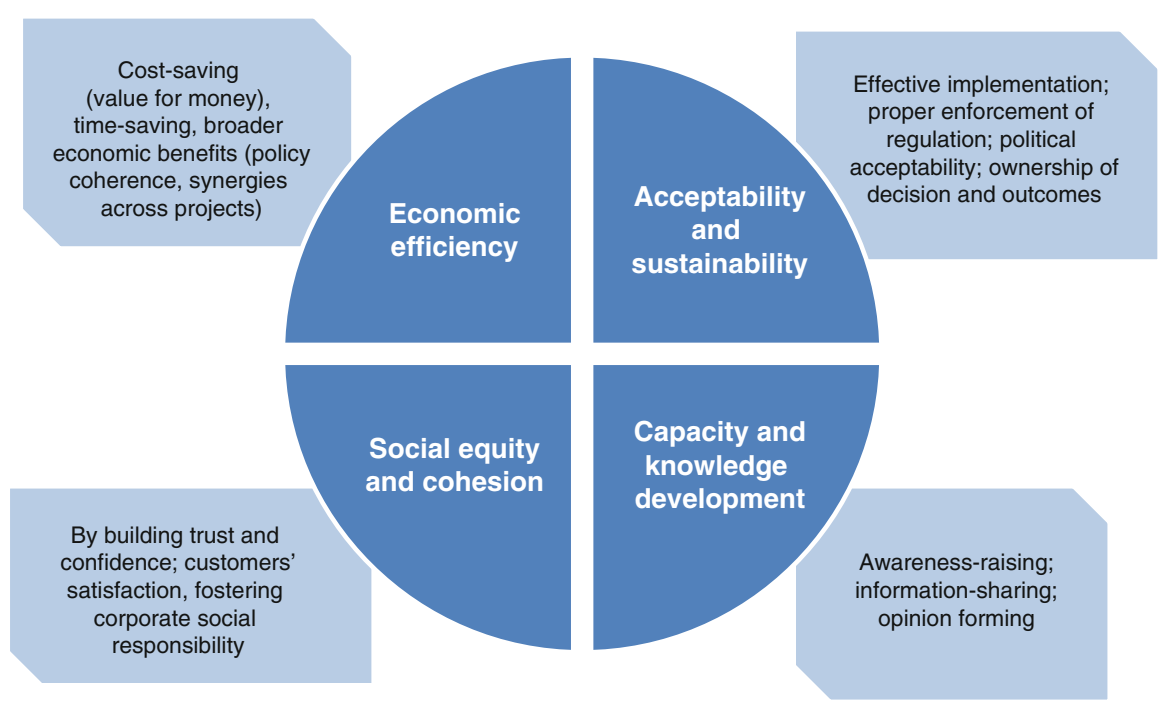

Fig. 3.10 Four types of long-term benefits of stakeholder engagement (Source: OECD (2015a))

Evidence from the survey and case studies highlights the fact that stakeholder engagement is an investment. Decision-makers are inclined to conduct discussions, consultations and exchange of opinions that can inflate some costs, be they direct, indirect, monetary or nonmonetary (Fig. 3.9). These costs relate to delays in the decision-making process, operational expenses (facilities, travel, staff, overtime, etc.) and the production and disclosure of the required information.

The process of engaging stakeholders may be more costly than the absence of consultation. However, dialogue and cooperation amongst stakeholders allows testing and refining of policies and projects and thus can yield short- and long-term benefits (Fig. 3.10). Short-term benefits relate to the outcomes of engagement such as better quality decision-making, increased willingness of stakeholders to collabo- 
rate to solve common water problems or greater support for the implementation of a water project or policy.

Long-term benefits relate to improved understanding and awareness of flood risks, more confidence in governments' decisions or capacity building. Overall, benefits can be clustered into four types:

- Acceptability and sustainability, in terms of effective implementation of water policy and projects, proper enforcement of regulation, political acceptability and ownership of decision and outcomes

- Social equity and cohesion, which is related to trust, confidence and customer satisfaction, as well as corporate social responsibility

- Capacity and knowledge development, which emanates from raising greater awareness, sharing information and forming opinions

- Economic efficiency, as it can assist in optimising cost saving, value for money and time saving, as well as broader economic benefits related to greater policy coherence and synergies across sectors and projects.

Conducting evaluations on the costs and benefits of stakeholder engagement can provide the evidence to effectively guide decision-making and policy/project implementation with tangible data and analyses. Different costs and benefits accrue to different stakeholder groups at different times and require managing trade-offs to ensure successful engagement processes and outcomes. There is a dearth of knowledge on the distributional impacts of stakeholder engagement. The danger is the potentially inequitable distribution of the benefits of engagement.

The sustainability of stakeholder engagement will not only depend on the net difference between aggregate costs and benefits, but also on how they are distributed between stakeholders and on stakeholders' willingness to bear them. Also, water policy reforms and large projects can induce important adjustment costs, especially in the short term, whilst the benefits of such initiatives may only become visible in the long term. It is crucial to critically reflect upon the ratio of costs and benefits during engagement processes and determine the appropriate trade-offs related to this dual temporality.

\subsection{Conclusion: OECD Necessary Conditions for Inclusive Water Governance}

Evidence presented in this chapter demonstrates that decision-makers who adopt a systemic, inclusive approach to water governance are likely to get a better return on the time and resources they invest. They will also be better equipped to handle stakeholder issues and risks more effectively.

For engagement processes to be relevant, a careful balance is required between what they try to achieve, the resources they require and whether they succeed in reaching the intended objectives. Decision-makers at all levels have a critical role to play in establishing the enabling environment for result-oriented, effective and 
impactful stakeholder engagement. Although engagement processes cannot be easily replicated from one context to another, the OECD proposes the following conditions for creating the enabling environment for inclusive water governance:

1. Map all stakeholders who have a stake in the outcome or who are likely to be affected, as well as their responsibility, core motivations and interactions. Stakeholder mapping should be done in relation to a specific issue and be updated on a regular basis. Such mapping should pay attention to newcomers, players outside the water sector and traditionally underrepresented groups. This is critical to ensure that all stakeholders are identified and properly involved throughout the policy/project cycle. Finding the right balance between inclusiveness and empowerment of stakeholders is also important. Engagement processes (and related mechanisms) need to accommodate the needs of stakeholders with varying levels of interests and resources to ensure inclusivity and accessibility. Risks related to consultation capture from overrepresented categories to the detriment of unheard voices, as well as risks of prejudice against a particular category of stakeholders deserve careful consideration. Equity between present and future generations in a perspective of sustainability should be promoted. Thus, disaggregated data on gender, age economic status and the level of impact of proposed policies and measures are crucial.

2. Define the ultimate line of decision-making, the objectives of stakeholder engagement and the expected use of inputs. Clarifying the goals and reasons for engagement is the key to building mutual understanding and trust of how stakeholders may be involved in the process and for informed stakeholders to provide quality contributions in line with expectations. In an engagement process with carefully set objectives, stakeholder engagement can make a meaningful contribution to the formulation of river basin plans at the watershed level, service delivery, awareness-raising (e.g. on water costs, risks, future trends), auditing, risk mapping, as well as performance monitoring. Similarly, the authority responsible for taking decisions, and its willingness to take stakeholders' ideas on board in doing so, should be clearly identified to enhance confidence in the value of the process. Transparency and accountability in how the engagement process is designed and implemented (e.g. stakeholder mapping methods, use of stakeholders' inputs) are crucial to improve credibility and legitimacy and to build trust amongst the stakeholders involved. Diligent work is necessary to ensure that the engagement process is fair and equitable and to reliably engage stakeholders.

3. Allocate proper financial and human resources and share requisite information for result-oriented stakeholder engagement. Improving the overall contribution to substantive discussions and decision-making requires access to timely and understandable information (be it cultural, scientific, traditional, etc.), technical expertise, experience sharing and funding in the right format and in good time (planning) to realistically and effectively participate. Supporting two-way information-sharing through consistent and appropriate communication channels, including web-based technologies when feasible, is key. The 
financial affordability of the engagement process is also important to ensure the effective engagement of all those that have a stake; convey accurate, trusted and accessible information to diverse sectors; foster opinion-forming within and across stakeholder groups; and build support to the process. In order to interpret and apply these resources and the information gathered, competences and capabilities need to be developed at all levels to enable sustainable stakeholder engagement (e.g. skills, social learning).

4. Regularly assess the process and outcomes of stakeholder engagement to learn, adjust and improve accordingly. Such evaluation and monitoring can resort to fact-based and perception-based tools and indicators and be carried out by targets, promoters and/or third parties. Results should be disclosed to increase accountability, provide insight into the success of the engagement process in reaching its intended objectives and learn from experience to improve practice in the future. Evaluation should not be limited to ex ante and ex post assessment but remain an ongoing process throughout the policy/project cycle. Stakeholder engagement can yield benefits in terms of resilience, sustainability, cohesion, acceptability, capacity and efficiency. However, it can also delay decisionmaking and implementation and generate different types of material (monetary and nonmonetary), process, reputational and social costs. Assessing the costs and benefits of engagement processes can assist in ensuring that all interests, including those of underrepresented stakeholders, are respected regarding the distribution of impacts, compensation and benefits. Mitigation measures are required to reduce costs and to set the right incentives whilst managing the dual short-term/long-term temporality.

5. Embed engagement processes in clear legal and policy frameworks, organisational structures/principles and responsible authorities. There is no water governance without governance at large. Similarly, there can be no effective stakeholder engagement without proper incentives for bottom-up and inclusive policy-making. A clear set of rules, platforms and vehicles for doing so is critical to move from reactive to proactive and systematic stakeholder engagement in the water sector. However, institutionalisation increases the risk of engagement 'fatigue' and/or 'capture' from overrepresented categories to the detriment of unheard voices. It should be flexible to take into consideration place-based needs and changing circumstances whilst fostering a change in the 'mindset', daily practices, professional skills and culture of decision-making. Provisions for stakeholder engagement should be aligned coherently and holistically across the water chain and policy domains related to water.

6. Customise the type and level of engagement to the needs and keep the process flexible to changing circumstances. Stakeholder engagement tools and mechanisms work differently across places, times, objectives and stages of the policy/project cycle. They should be tailored to each context (geographic, socioeconomic, cultural), type of stakeholder concerned, policy goal targeted and place-based needs to accommodate varying levels of interest and resources from stakeholders and consider other options as needs arise. Water governance systems are complex and in a state of constant flux, where change is dynamic and 
often unpredictable. Engagement processes therefore need to enable multiple stakeholders to respond and adapt to uncertainty and should remain flexible to manage risks and resilient to adapt to changing environments. Lessons can be learnt from failure in engagement approaches in terms of management of complexity and how to bring about fundamental change.

\section{References}

Abelson, J., \& Gauvin, F. P. (2006). Assessing the impacts of public participation: Concepts, evidence and policy implications (Research report P/06). Ottawa: Canadian Policy Research Networks.

Arnstein, S. R. (1969). A ladder of citizen participation. Journal of the American Institute of Planners, 35(4), 216-224.

Brown, M., \& Wyckoff-Baird, B. (1992). Designing integrated conservation and development projects. Washington, DC: Biodiversity Support Program.

Fung, A. (2006). Varieties of participation in complex governance. Public Administration Review, 66(Supplement S1), 66-75. http://dx.doi.org/10.1111/j.1540-6210.2006.00667.x

Guimarães-Pereira, A., Rinaudo, J. D., Jeffrey, P., Blasuqes, J., Corral-Quintana, S. A., Courtois, N., Funtowicz, S., \& Petit, V. (2003). ICT tools to support public participation in water resources governance and planning: Experiences from the design and testing of a multi-media platform. Journal of Environmental Assessment Policy and Managemet, 5(3), 395-420. http:// dx.doi.org/10.1142/S1464333203001383

OECD. (2011). Water governance in OECD countries: A multi-level approach (OECD studies on water). Paris: OECD Publishing. http://dx.doi.org/10.1787/9789264119284-en

OECD. (2012). OECD environmental outlook to 2050: The consequences of inaction. Paris: OECD Publishing. http://dx.doi.org/10.1787/9789264122246-en

OECD. (2014). Water governance in the Netherlands: Fit for the future? (OECD studies on water). Paris: OECD Publishing. http://dx.doi.org/10.1787/9789264102637-en

OECD. (2015a). Stakeholder engagement for inclusive water governance. Paris: OECD Publishing. http://dx.doi.org/10.1787/9789264231122-en

OECD. (2015b). OECD Principles on water governance. Paris: OECD Publishing. http://www. oecd.org/governance/oecd-principles-on-water-governance.htm

Pretty, J. (1995). Participatory learning for sustainable agriculture. World Development, 23(8), $1247-1263$.

Smith, D. H. (1983). Synanthrometrics: On progress in the development of a general theory of voluntary action and citizen participation. In D. H. Smith \& J. Van Til (Eds.), International perspectives on voluntary action research. Washington, DC: University Press of America.

United Nations Development Programme (UNDP) Water Governance Facility, Stockholm International Water Institute, \& Water Integrity Network. (2013). User's guide on assessing water governance. Denmark: United Nations Development Programme.

Wehn, U., \& Evers, J. (2014). Citizen observatories of water: Social innovation via eParticipation? In Proceedings of the ICT4 Sustainability conference (ICT4S), Stockholm, 24-27 August 2014, nominated for best paper award.

Wehn, U., Rusca, M., \& Evers, J. (2014). Participation in flood risk management and the potential of citizen observatories: A governance analysis. In Abstracts of the international conference on flood management, 16-18 September, Sao Paulo, Brazil.

Yee, S. (2010). Stakeholder engagement and public participation in environmental flows and river health assessment. Australia-China Environment Development Partnership, Project code P0018, May 2010. 
Open Access This chapter is distributed under the terms of the Creative Commons AttributionNoncommercial 2.5 License (http://creativecommons.org/licenses/by-nc/2.5/) which permits any noncommercial use, distribution, and reproduction in any medium, provided the original author(s) and source are credited.

The images or other third party material in this chapter are included in the work's Creative Commons license, unless indicated otherwise in the credit line; if such material is not included in the work's Creative Commons license and the respective action is not permitted by statutory regulation, users will need to obtain permission from the license holder to duplicate, adapt or reproduce the material.

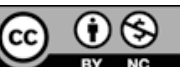

